\title{
Ischemic stroke in young adults: an overview of etiological aspects
}

Acidente vascular cerebral isquêmico em adultos jovens: considerações etiológicas

Fábio luji Yamamoto

\begin{abstract}
Stroke affects mainly people aged over 65 years, and atherosclerosis predominates as the main etiopathogenic factor in ischemic stroke (IS). On the other hand, cardiac embolism and arterial dissection are the most frequent causes of IS in patients aged less than 45 years. However, inappropriate control of traditional vascular risk factors in young people may be causing a significant increase of atherosclerosis-related IS in this population. Furthermore, a variety of etiologies, many of them uncommon, must be investigated. In endemic regions, neurocysticercosis and Chagas' disease deserve consideration. Undetermined cause has been still reported in as many as one third of young stroke patients.
\end{abstract}

Key words: stroke, brain ischemia, young adult.

RESUMO

A doença aterosclerótica é o fator etiopatogênico mais importante no acidente vascular cerebral isquêmico (AVCI), afecção que acomete predominantemente pessoas acima da sétima década de vida. Entretanto, nos adultos jovens a aterosclerose exibe frequência menor, sendo a embolia de origem cardíaca e as dissecções arteriais as causas mais comuns de AVCl em pacientes com até 45 anos de idade. Porém, o controle inadequado dos fatores de risco vascular nas faixas mais jovens da população pode estar levando à elevação significativa no número de infartos cerebrais associados à aterosclerose nessa faixa etária.Uma ampla gama de fatores etiológicos, muitos deles raros, deve ser considerada no seu diagnóstico diferencial. Em áreas endêmicas, doenças infecciosas como a neurocisticercose e a doença de Chagas devem ser lembradas ao se estabelecer o diagnóstico etiológico. Os infartos cerebrais de causa indeterminada ainda são parcela significativa nos AVCls em adultos jovens.

Palavras-Chave: acidente vascular cerebral, isquemia cerebral, adulto jovem.

Ischemic stroke (IS) in young adults is reported as uncommon, comprising less than $10 \%$ of all stroke patients ${ }^{1}$. However, In our clinical practice, we are faced not infrequently with patients aged less than 45 years who suffered a stroke, many of them with no risk factors for atherosclerosis and no ultimate clear etiological diagnosis even after a thorough investigation. This diagnostic challenge is one of the main scopes of studying and researching mechanisms of brain ischemia in young adults in addition to the dramatic personal, familial, and socio-economic consequences by affecting individuals at the top of their productive age.

Although cardioembolism and cervicocephalic arterial dissection have been established as principal etiological factors of IS in young adults ${ }^{2}$, a systematic diagnostic approach must be applied to all patients, regarding the great number of potential causes in this group and the multifactorial nature in many of these patients.
Despite more accurate diagnostic tools recently acquired in vascular imaging, hematological and genetic studies, currently, the number of young patients with cryptogenic IS remains high, performing 30-40\% $\%^{3,4}$.

Considered an unusual cause of IS in the young two decades ago $^{5}$, atherosclerosis has gaining projection by recent reports of significant raise in traditional risk factors as hypertension, diabetes, obesity, dyslipidemia and tabagism among hospitalized adolescents and young adults ${ }^{6 .}$

Table 1 shows the main categorizations of etiologic subtypes of IS in young adults that must be considered in every young patient with IS.

\section{NONATHEROSCLEROTIC ANGIOPATHIES}

Cervicocephalic arterial dissections are by far the commonest cause of IS within the nonatherosclerotic angiopathies

Cerebrovascular Diseases Study Group, Division of Neurology, Hospital das Clínicas da Faculdade de Medicina da Universidade de São Paulo, São Paulo SP, Brazil. Correspondence: Fábio luji Yamamoto; Avenida Dr. Eneas de Carvalho Aguiar 255/5084; 05403-000 São Paulo SP - Brasil; E-mail:fabioyamamoto@hcnet.usp.br Conflict of interest: There is no conflict of interest to declare.

Received 09 January 2012; Accepted 17 January 2012 
and rank first or second regarding all etiologies of IS in young adults $^{5,7-9}$. The increased awareness and the routine use of less invasive neuroimaging studies, as computed tomography and magnetic resonance imaging, have permitted to establish this diagnosis in a raising number of patients. Angiographic evidence of fibromuscular dysplasia (FMD) is found in about $15 \%$ of the patients with cervical internal carotid dissection ${ }^{10,11}$, and simultaneous bilateral carotid dissection was described in $14 \%$ of the patients, most with an underlying arteriopathy, mainly $\mathrm{FMD}^{12}$.

Table1. Etiology of ischemic stroke in young adults.

\begin{tabular}{|c|c|}
\hline \multirow{8}{*}{$\begin{array}{l}\text { Nonatherosclerotic } \\
\text { angiopathies }\end{array}$} & Cervicocephalic arterial dissection \\
\hline & Fibromuscular dysplasia \\
\hline & Moyamoya disease \\
\hline & Angiitis \\
\hline & $\begin{array}{l}\text { Genetic and hereditary diseases (Fabry's disease, } \\
\text { CADASIL, MELAS, HERNS) }\end{array}$ \\
\hline & Reversible cerebral vasoconstriction syndrome \\
\hline & Susac's syndrome \\
\hline & Sneddon's syndrome \\
\hline \multirow[t]{10}{*}{ Cardioembolism } & Rheumatic valvular disease \\
\hline & Patent foramen ovale \\
\hline & Atrial septal aneurysm \\
\hline & Prosthetic valve \\
\hline & Infective endocarditis \\
\hline & Arrhythmia (atrial fibrillation) \\
\hline & Dilated cardiomyopathy (Chagas' disease) \\
\hline & Mitral valve prolapse \\
\hline & Atrial myxoma \\
\hline & Marantic and Libman-Sacks endocarditis \\
\hline \multicolumn{2}{|l|}{$\begin{array}{l}\text { Large-artery } \\
\text { atherosclerosis }\end{array}$} \\
\hline \multicolumn{2}{|l|}{$\begin{array}{l}\text { Small-vessel } \\
\text { disease }\end{array}$} \\
\hline \multirow{8}{*}{$\begin{array}{l}\text { Hematologic } \\
\text { conditions } \\
\text { (prothrombotic } \\
\text { states) }\end{array}$} & Antiphospholipid syndrome \\
\hline & Hyperhomocysteinemia \\
\hline & Sickle cell disease \\
\hline & Myeloproliferative disorders \\
\hline & Factor V Leiden \\
\hline & Prothrombin 20210A mutation \\
\hline & Protein C, protein S deficiency \\
\hline & Antithrombin III deficiency \\
\hline \multicolumn{2}{|l|}{ Migraine stroke } \\
\hline Cryptogenic stroke & \\
\hline
\end{tabular}

On the other hand, FMD as a rare nonatheromatous, noninflammatory systemic angiopathy more common in young and middle-aged women, may be an incidental finding in asymptomatic patients ${ }^{13}$.

Moyamoya disease affects mainly Asian people, but is described throughout the world ${ }^{14}$. Ischemic stroke predominates in children whereas intracranial hemorrhage is usually seen in adults. Our personal experience through multiethnic population in Brazil points to a greater frequency of moyamoya disease in Japanese descendants.

Vasculitides of the central nervous system (CNS) are often reminded when differential diagnosis of IS in young adults is discussed, however their diagnostic confirmation seldom occurs. The main reasons for this failure lie on their rarity and pleomorphic clinical symptomatology since cerebral angiitis usually reveals a subacute or progressive encephalopathy with multifocal neurologic deficits ${ }^{15}$. Therefore, isolated angiitis of the CNS and systemic vasculitides uncommonly open with acute stroke episodes.

In endemic regions, neurocysticercosis must be considered in young adults with small or large-vessel angiitis. Subarachnoid cysts near the ischemic lesion, associated with inflammatory changes in the wall of neighbouring intracranial arteries, are the hallmark of this condition ${ }^{16}$.

Table 2 shows a brief classification of the vasculitides that affect the CNS.

Fabry's disease ${ }^{17}$, cerebral autosomal dominant arteriopathy with subcortical infarcts and leukoencephalopathy $(\mathrm{CADASIL})^{18}$, mitochondrial encephalopathy with lactic acidosis and stroke-like episodes (MELAS) ${ }^{19}$, and hereditary endotheliopathy with retinopathy, nephropathy and stroke $(\text { HERNS })^{20}$ are genetic and hereditary diseases that deserve consideration in the differential diagnosis of IS in young adults.

Susac's syndrome (retinocochleocerebral vasculopathy) ${ }^{21}$ and Sneddon's syndrome (livedo reticularis associated with cerebrovascular events) ${ }^{22}$, with or without antiphospholipid antibodies, are other rare noninflammatory angiopathies that occur predominantly in young adults.

Reversible cerebral vasoconstriction syndrome, also known as Call-Fleming syndrome or postpartum angiopathy, is commonly secondary to exposure to vasoactive substances and to the postpartum state. Ischemic stroke and

Table 2. Main subtypes of central nervous system vasculitides.

1. Isolated central nervous system angiitis

2. Collagen vascular diseases (polyarteritis nodosa, Churg-Strauss angiitis, systemic lupus erythematosus, scleroderma, Wegener's granulomatosis, rheumatoid arthritis, Sjögren's disease)

3. Giant cell arteritis (temporal arteritis, Takayasu's disease)

4. Hypersensitivity vasculitis (Henoch-Schönlein purpura, cryoglobulinemia)

5. Behçet's disease

6. Infectious (syphilis, bacterial, fungal, tuberculosis, varicela zoster, HIV, neurocysticercosis)

7. Toxic (amphetamines, cocaine, crack, heroin, phenylpropanolamine, lysergic acid diethylamide)

8. Neoplasm-related 
transient ischemic attacks occur later than hemorrhagic strokes, mainly during the second week ${ }^{23}$.

\section{CARDIOGENIC EMBOLISM}

Cardioembolism, one of the most important mechanisms of IS in the young, is worthy of consideration in all patients with this condition. The proportion of cardioembolic strokes in young adults varies from $20 \%$ to one third ${ }^{2,4,5,8}$.

In the past, mainly in developing countries, rheumatic valvular disease was an important cause of embolism, but currently patent foramen ovale (PFO) has gained relevance among cardiac sources of embolism, being the most frequently reported cause of cardioembolic stroke in young adults $^{24,25}$.

The prevalence of $\mathrm{PFO}$ in the general population is high, about one fourth, decreasing gradually with increased age, from $34 \%$ during the first 3 decades to $20 \%$ in the $9^{\text {th }}$ decade ${ }^{26}$.

Paradoxical venous embolism through right to left shunt is considered the commonest mechanism of stroke in this situation, but in situ thrombosis within the atrial septum and propensity of developing arrhythmias such as atrial fibrillation are alternative mechanisms ${ }^{27}$.

Several case-control studies showed that the presence of PFO in patients younger than 55 years of age is significantly associated with cryptogenic stroke ${ }^{28}$, and associated prothrombotic state or concurrent atrial septal aneurysm seems to increase their stroke risk.

Chagas' disease (CD) is an independent risk factor for IS $^{29}$ and dilated cardiomyopathy and arrhythmias cause cardioembolism in most of the patients with $\mathrm{CD}$ and stroke. However, about $20-25 \%$ of patients with IS and T cruzi infection have cryptogenic stroke. Thus, all patients with cryptogenic or cardioembolic stroke should be screened for T. cruzi infection if they live in or have emigrated from endemic areas, mainly South America ${ }^{30}$.

Chronic inflammation in CD has been hypothesized as a trigger to cause vascular damage and stroke in this group of cryptogenic stroke patients with no significant systolic dysfunction or cardiac arrhythmias ${ }^{31}$.

\section{LARGE-ARTERY ATHEROSCLEROSIS}

Large-artery atherosclerosis has been shown to be an infrequent cause of IS in young adults, usually reaching values below 10\% 5,9,32-34. However, our experience in São Paulo corroborates the findings of Zétola et al. in Curitiba, Brazil, who found higher percentages of atherothrombotic stroke in young adults associated with high prevalence of arterial hypertension, smoking, hypercholesterolemia, diabetes mellitus and alcohol abuse $\mathrm{s}^{35,36}$. Thus, for reducing the burden of stroke also in young populations, it seems very cost-effective prioritizing interventions targeting control of modifiable risk factors, especially in developing countries and minorities in high income nations ${ }^{37}$.

High percentage of large artery atherosclerosis was also found in Korean and Malaysian young patients, 20.8 and $28.3 \%$ respectively ${ }^{38,39}$, and significant intracranial stenosis was demonstrated in $26.5 \%$ of Taiwanese young people, being premature atherosclerosis the most common cause of intracranial stenosis ${ }^{34}$.

\section{SMALL-VESSEL DISEASE}

Although small-vessel disease characteristically affects older diabetic or hypertensive people, high percentages (17-32\%) were reported from Asian and US black patients, suggesting race-ethnic influences on this subtype of young stroke patients ${ }^{34,38-40}$. A Brazilian series points to lower numbers $(12 \%)^{32}$, similar to most published studies ${ }^{3,9,32,41,42}$.

In neurocysticercosis, endarteritis may cause lacunar syndromes by involvement of small penetrating arteries. Therefore, this diagnosis should be considered in young adults with small-vessel disease who originate from endemic $\operatorname{areas}^{43}$.

\section{HEMATOLOGIC CONDITIONS}

Only 1-4\% of IS are related to acquired and genetic thrombophilias, but these numbers seem higher in young adults ${ }^{44}$. The most common acquired thrombophilia associated to IS in the young is antiphospholipid syndrome. Antiphospholipid antibodies, particularly lupus anticoagulant, are an independent risk factor for IS in young adults ${ }^{45}$. Genetic prothrombotic states play an important role in young patients with cerebral venous thrombosis, but thrombophilia alone rarely causes arterial occlusions ${ }^{46}$.

\section{MIGRAINE}

Considering that migraine affects about $15 \%$ of the adult population, migrainous infarct is a rare event in young adults.

Migrainous infarction is defined as an IS occurring during a typical attack of migraine with aura, except that these aural symptoms persist for more than 60 minutes. Moreover, neuroimaging has to confirm an IS in the vascular topography of the aura, mainly in the territory of the posterior cerebral artery, and other possible causes of IS must be excluded by appropriate investigation ${ }^{47}$. 
The mechanisms involved in the migraine-induced IS are poorly understood. The neuronal spreading depression that supports the aural symptoms does not seem sufficient to trigger ischemic injury by decreasing the cerebral blood flow ${ }^{48}$.

Patients with migrainous infarcts usually disclose multiple related vascular risk factors as smoking and oral contraceptive use. Drugs used in migraine treatments, particularly high dose vasoconstrictors, as ergot alkaloids, might trigger IS.

Meta-analysis of observational studies suggested elevated stroke risk in patients with migraine, particularly those with aura (relative risk 2.27, 95\% confidence interval 1.61 to 3.19). In migraineurs taking oral contraceptives, the stroke risk was very high (relative risk 8.72, 95\% confidence interval 5.05 to $15.05)^{49}$.

The increased risk of IS in migraineurs, especially young women with aura, probably has multifactorial basis, including migrainous infarctions, arterial dissection, fibromuscular dysplasia, PFO, drug induced infarcts, prothrombotic states and genetic factors ${ }^{48,50}$.

\section{CRYPTOGENIC STROKE}

Ischemic young stroke patients with undetermined etiology varied from $16 \%$ to almost half when TOAST ${ }^{51}$ criteria were used ${ }^{3,32-34,38,52}$. These high numbers may be explained in part by the insufficient extent and timing of the investigation, because transient and completely reversible phenomena may underlie the etiopathogenesis of many cases of cryptogenic stroke. For example, cerebral embolism caused by paroxystic asymptomatic arrhythmias like atrial fibrillation can occur in young patients with acute alcoholic intoxication ${ }^{53}$.

Furthermore, TOAST classification may lead to overrating the group of undetermined origin, as patients with two or more potential causes fall in this group, joining to the patients with incomplete investigation and those with no evident cause despite complete evaluation.

Thus, more accurate etiologic subtyping of IS, like the recent SSS-TOAST ${ }^{54}$ and A-S-C-O classifications ${ }^{55}$, would possibly impact on reducing the high percentages of strokes of undetermined cause found in studies that applied the TOAST classification.

\section{FINAL REMARKS}

Young patients with IS are often a diagnostic challenge. A myriad of etiologic possibilities arise in these patients, attenuating the relative importance of atherosclerosis in this age group. However, premature atherosclerosis has arising as a major concern in young stroke patients, considering their high observed prevalence of vascular risk factors.

Differing from the standard IS patients, diagnostic workup in the young is usually extensive and may involve invasive investigation, as cerebral angiography and brain biopsy in suspected cases of isolated angiitis of the CNS. Moreover, unusual therapies for stroke patients can be indicated, like immunosuppression in patients with systemic and isolated vasculitis of the CNS, and revascularization procedures for moyamoya disease.

\section{References}

1. Grau AJ, Weimar C, Buggle F, et al. Riskfactors, outcome, and treatment in subtypes of ischemic stroke: the German Stroke Data Bank. Stroke 2001;32:2559-2566

2. Barinagarrementeria F, Figueroa T, Huebe J, Cantú C. Cerebral infarction in people under 40 years. Etiologic analysis of 300 cases prospectively evaluated. Cerebrovasc Dis 1996;6:75-79.

3. Lipska K, Sylaja PN, Sarma PS, et al. Risk factors for acute ischaemic stroke in young adults in South India.J Neurol Neurosurg Psychiatry 2007;78:959-963.

4. Putaala J, Metso AJ, Metso TM, et al. Analysis of 1008 consecutive young patients aged 15 to 49 with first-ever ischemic stroke: the Helsinki Young Stroke Registry. Stroke 2009;40: 1195-1203.

5. Bogousslavsky J, Pierre P. Ischemic stroke in patients under age 45 Neurol Clin 1992;10:113-124.

6. George MG, Tong X, Kuklina EV, Labarthe DR. Trends in stroke hospitalizations and associated risk factors among children and young adults, 1995-2008. Ann Neurol 2011;70:713-721.

7. Gautier JC, Pradat-Diehl P, Loron P, et al. Accidents vasculaires cérébraux des sujets jeunes: une étude de 133 patients âgés de 9 à 45 ans. Rev Neurol (Paris) 1989;145:437-442.

8. Kristensen B, MalmJ, Carlberg B, et al. Epidemiology and etiology of ischemic stroke in young adults aged 18 to 44 years in northern Sweden. Stroke 1997;28:1702-1709.
Leys D, Bandu L, Hénon H, et al. Clinical outcome in 287 consecutive young adults (15 to 45 years) with ischemic stroke. Neurology 2002;59:26-33.

10. Mokri B,SundtTM Jr, Houser OW, Piepgras DG. Spontaneous dissection of the cervical internal carotid artery. Ann Neurol 1986;19:126-138.

11. SchievinkWI. Current concepts: spontaneous dissection of the carotid and vertebral arteries. N Engl J Med 2001;344:898-906.

12. Hart RG, Easton JD. Dissections of cervical and cerebral arteries. Neurol Clin 1983;1:155-182

13. Piechowski-Józwiak B, Bogousslavsky J. Cervicocephalic fibromuscular dysplasia. In: Mohr JP, Choi DW, Grotta JC, Weir B, Wolf PA (Eds). Stroke. Pathophysiology, diagnosis, and management. $4^{\text {th }}$ ed. Philadelphia: Churchill Livingstone;2004:619-628.

14. Kuroda S, Houkin K. Moyamoya disease: current concepts and future perspectives. Lancet Neurol 2008;7:1056-1066.

15. Ferro JM. Vasculitis of the central nervous system. J Neurol 1998;245:766-776.

16. Cantú C, Barinagarrementeria F. Cerebrovascular complications of neurocysticercosis. Clinical and neuroimaging spectrum. Arch Neurol 1996;53:233-239.

17. Sims K, Politei J, Banikazemi M, Lee P. Stroke in Fabry disease frequently occurs before diagnosis and in the absence of other clinical events: natural history data from the Fabry Registry. Stroke 2009;40:788-794 
18. Dichgans M, Mayer M, Uttner I, et al. The phenotypic spectrum of CADASIL: clinical findings in 102 cases. Ann Neurol 1998;44:731-739.

19. Pavlakis SG, Phillips PC, DiMauro S, De Vivo DC, Rowland LP. Mitochondrial myopathy, encephalopathy, lactic acidosis, and strokelike episodes: a distinctive clinical syndrome. Ann Neurol 1984;16:481-488.

20. Jen J, Cohen $A H$, Yue Q, et al. Hereditary endotheliopathy with retinopathy, nephropathy, and stroke (HERNS). Neurology 1997;49:1322-1330.

21. Susac JO. Susac's syndrome: the triad of microangiopathy of the brain and retina with hearing loss in young women. Neurology 1994;44: 591-593.

22. Stockhammer G,Felber SR,ZelgerB, etal.Sneddon's syndrome:diagnosis by skin biopsy and MRI in 17 patients. Stroke 1993;24:685-690.

23. Ducros A, Boukobza M, Porcher R, Sarov M, Valade D, Bousser $M G$. The clinical and radiological spectrum of reversible cerebral vasoconstriction syndrome. A prospective series of 67 patients. Brain 2007;130:3091-3101.

24. Lechat P, Mas JL, Lascault G, et al. Prevalence of patent foramen ovale in patients with stroke. N Engl J Med 1988;318:1148-1152.

25. Larrue V, Berhoune N, Massabuau P, et al. Etiologic investigation of ischemic stroke in young adults. Neurology 2011;76:1983-1988.

26. Hagen PT, Scholz DG, Edwards WD. Incidence and size of patent foramen ovale during the first 10 decades of life: an autopsy study of 965 normal hearts. Mayo Clin Proc 1984;59:17-20.

27. Kizer JR, Devereux RB. Clinical practice. Patent foramen ovale in young adults with unexplained stroke. N Engl J Med 2005;353:2361-2372.

28. Overell JR, Bone I, Lees KR. Interatrial septal abnormalities and stroke. A meta-analysis of case-control studies. Neurology 2000;55: $1171-1179$.

29. Oliveira-Filho J, Viana LC, Vieira-de-Melo RM, et al. Chagas disease is an independent risk factor for stroke. Stroke 2005;36:2015-2017.

30. Carod-Artal FJ, Gascon J. Chagas disease and stroke. Lancet Neurol 2010;9:533-542.

31. Oliveira-Filho J. Stroke and brain atrophy in chronic Chagas disease patients.A new theory proposition. Dement Neuropsychol 2009;3:22-26.

32. Adams HP Jr, Kappelle LJ, Biller J, et al. Ischemic stroke in young adults. Experience in 329 patients enrolled in the lowa Registry of stroke in young adults. Arch Neurol 1995;52:491-495.

33. Siqueira Neto JI, Santos AC, Fabio SR, Sakamoto AC. Cerebral infarction in patients aged 15 to 40 years. Stroke 1996;27:2016-2019.

34. Lee TH, Hsu WC, Chen CJ, Chen ST. Etiologic study of young ischemic stroke in Taiwan. Stroke 2002;33:1950-1955.

35. Tinone G, Yamamoto FI, Comerlatti LR, Hirsch R, Scaff M. Cerebral infarction in young adults: a survey of 121 Brazilian patients. Abstracts of the International Stroke Society Second World Congress of Stroke. Washington; 1992:74.

36. Zétola VHF, Nóvak EM, Camargo CHF, et al. Acidente vascular cerebral em pacientes jovens. Análise de 164 casos. Arq Neuropsiquiatr 2001;59:740-745.
37. Trimble B, Morgenstern LB. Stroke in minorities. Neurol Clin 2008;26:1177-1190.

38. Kwon Su, Kim JS, Lee JH, Lee MC. Ischemic stroke in Korean young adults. Acta Neurol Scand 2000;101:19-24.

39. Tan KS, Tan CT, Churilov L, Mackay M, Donnan GA. Ischaemic stroke in young adults: a comparative study between Malaysia and Australia. Neurology Asia 2010;15:1-9.

40. Qureshi Al, Safdar K, Patel M, Janssen RS, Frankel MR. Stroke in young black patients. Risk factors, subtypes, and prognosis. Stroke 1995;26:1995-1998.

41. Williams LS, Garg BP, Cohen M, Fleck JD, Biller J. Subtypes of ischemic stroke in children and young adults. Neurology 1997;49:1541-1545.

42. Hoffmann M. Stroke in the young in South Africa - an analysis of 320 patients. S Afr Med J 2000;90:1226-1237.

43. Barinagarrementeria $\mathrm{F}$, Del Brutto $\mathrm{OH}$. Lacunar syndrome due to neurocysticercosis. Arch Neurol 1989;46:415-417.

44. Fields MC, Levine SR. Thrombophilias and stroke: diagnosis, treatment, and prognosis. J Thromb Thrombolysis 2005;20:113-126.

45. Brey RL. Antiphospholipid antibodies in young adults with stroke. J Thromb Thrombolysis 2005;20:105-112.

46. Morris JG, Singh S, Fisher M. Testing for inherited thrombophilias in arterial stroke. Can it cause more harm than good? Stroke 2010;41:2985-2990.

47. Headache Classification Committee of the International Headache Society. The International Classification of Headache Disorders. $2^{\text {nd }}$ edition. Cephalalgia 2004;24:1-160.

48. Bousser MG, Welch KMA. Relation between migraine and stroke. Lancet Neurol 2005;4:533-542.

49. Etminan M, Takkouche B, Isorna FC, Samii A. Risk of ischaemic stroke in people with migraine: systematic review and meta-analysis of observational studies. BMJ 2005;330:63-65.

50. Del Zotto E, Pezzini A, Giossi A, Volonghi I, Padovani A. Migraine and ischemic stroke: a debated question. J Cereb Blood Flow Metab 2008:28:1399-1421.

51. Adams HPJr, Bendixen BH, Kappelle LJ, et al. Classification of subtype of acute ischemic stroke. Definitions for use in a multicenter clinical trial. TOAST. Trial of Org 10172 in Acute Stroke Treatment. Stroke 1993;24:35-41.

52. Naess H, Nyland HI, Thomassen L, Aarseth J, Myhr KM. Etiology of and risk factors for cerebral infarction in young adults in western Norway: a population-based case-control study. Eur J Neurol 2004;11:25-30.

53. Hillbom M, Haapaniemi H, Juvela S, Palomäki H, Numminen H, Kaste M. Recent alcohol consumption, cigarette smoking, and cerebral infarction in young adults. Stroke 1995;26:40-45.

54. Ay H, Furie KL, Singhal A, Smith WS, Sorensen AG, Koroshetz WJ. An evidence-based causative classification system for acute ischemic stroke. Ann Neurol 2005;58:688-697.

55. Amarenco P, Bogousslavsky J, Caplan LR, Donnan GA, Hennerici MG. New approach to stroke subtyping: the A-S-C-O (phenotypic) classification of stroke. Cerebrovasc Dis 2009;27:502-508. 